\title{
Paisagem, estrutura e composição florística de um parque urbano em Manaus, Amazonas, Brasil
}

\author{
Landscape, structure and floristic composition of an urban park in Manaus, \\ Amazonas, Brazil
}

Eduardo da Silva Pinheiro ${ }^{1,3}$, Jan Feldmann Martinot ${ }^{1}$, Davi Grijó Cavalcante ${ }^{1}$, Mariza Alves de Macedo ${ }^{2}$, André Zumak Azevedo Nascimento ${ }^{1}$ \& Jenifer Pereira Castilho Marques ${ }^{1}$

\begin{abstract}
Resumo
A conservação dos ecossistemas de áreas protegidas inseridas em paisagens urbanas constitui-se um desafio para as instituições responsáveis por sua gestão. O conhecimento desses ecossistemas e de sua distribuição espacial são essenciais para direcionar seu manejo. O objetivo deste estudo consistiu em analisar o Parque Estadual Sumaúma, Manaus, AM, no contexto da ecologia de paisagens e caracterizar a composição florística e estrutural das unidades florestais da área. Trinta parcelas de $20 \times 20 \mathrm{~m}$ foram estabelecidas, e os indivíduos com DAP $>5 \mathrm{~cm}$ foram identificados e medidos. Foram registradas 196 espécies arbóreas, pertencentes a 134 gêneros e 58 famílias, refletindo uma alta diversidade florística. No Parque foram identificadas plantas exóticas e seis espécies ameaçadas de extinção. Métricas da paisagem foram analisadas para cinco unidades de paisagem: floresta de encosta, floresta de baixio, campo antrópico, solo exposto e edificações. Os índices de forma e dimensão fractal demonstraram que as paisagens florestais tendem para uma forma não-circular, o que indica a necessidade de maior controle de suas bordas. Estudos permanentes são necessários para a conservação das áreas de fragmentos florestais tendo em vista a manutenção de suas funções ecológicas e sociais além da recuperação de áreas alteradas o mais próximo possível dos ambientes florestais menos impactados.

Palavras-chave: Amazônia, fragmento florestal, métricas da paisagem, SIG.
\end{abstract}

\begin{abstract}
Ecosystem conservation of protected areas included in urban landscapes is a challenge for efficient management. Knowledge of these ecosystems and their spatial distribution is essential to guide conservation and restoration planning. We analyzed vegetation units and landscape metrics, as well as the structure and floristic composition of slope and lowland forests in Sumaúma State Park, Manaus, Amazonas, Brazil. Thirty plots $(20 \times 20 \mathrm{~m})$ were sampled, and the height and diameter of all individuals with $\mathrm{dbh}>5 \mathrm{~cm}$ were measured and the species identified. A record of 196 species belonging to 134 genera and 58 families was made, reflecting high diversity, although mainly for secondary vegetation. We identified exotic plants and six endangered species. Landscape metrics were calculated for the five landscapes units within the Park: slope forest, lowland forest, manmade grassland, bare soil and buildings. Shape and fractal dimension landscape indices for the two forest classes showed a tendency toward non-circular shape, which indicates the need to mitigate edge effects. Ongoing studies are needed to conserve areas of forest fragments in order to maintain their ecological and social functions and the recovery of degraded areas as close as possible to less impacted forest habitats.
\end{abstract}

Key words: Amazon, forest fragment, landscape metrics, GIS.

\section{Introdução}

As regiões Neotropicais concentram aproximadamente $57 \%$ de todas as florestas tropicais do mundo, as quais são reconhecidas como um importante repositório de diversidade biológica (Ayres et al. 2005). Em nível global a região Amazônica representa o maior trecho de floresta tropical não perturbada (Gascon et al. 2002). A cobertura florestal da Amazônia brasileira vem sofrendo alterações devido ao desflorestamento. Segundo INPE (2009), estima-se que até o ano de 2009 cerca de $20 \%\left(736.184,6 \mathrm{~km}^{2}\right)$ da cobertura 
florestal original tenham sido alteradas. No Brasil, os principais projetos para o monitoramento do desflorestamento da Amazônia tais como o PRODES e DETER, executados pelo INPE, não são realizados em áreas urbanas, onde a grande concentração de população humana também promove significativas alterações ambientais.

Na cidade de Manaus, metrópole localizada na Amazônia Central, o crescimento urbano ocorreu em áreas de florestas primárias, de forma desordenada ou por empreendimentos imobiliários autorizados (Rovere \& Crespo 2002). Segundo Costa et al. (2008) $29,6 \%$ da área urbana estão cobertos por floresta (13.492 ha), distribuídos em 443 fragmentos florestais.

Para Laurance et al. (2001) a redução da cobertura florestal e consequente fragmentação resultam na diminuição da biodiversidade e contribuem para o surgimento de ilhas de florestas isoladas. Contudo, a manutenção destes remanescentes florestais é de extrema importância, uma vez que suas condições ecológicas interferem nos índices de poluição do ar, conforto térmico e refúgio para fauna e flora (Bononi 2004; Lang \& Blaschke 2009).

Devido à dinâmica urbana da cidade de Manaus, são necessárias técnicas capazes de realizar diagnósticos e monitoramento das interrelações existentes entre os vários componentes ambientais para garantir a sustentabilidade no uso, ocupação e parcelamento dos espaços urbanos. A ecologia de paisagens é um instrumento que pode auxiliar as tomadas de decisão em planejamento ambiental, uma vez que permite a sistematização, análise da complexidade e multiplicidade dos fatores que atuam em um ambiente, além de possibilitar a integração dos conceitos de heterogeneidade espacial e escala na análise ecológica (Metzger 2002). O uso de Sistema de Informações Geográficas (SIG) e das técnicas de sensoriamento remoto tornou-se adequado para análise da paisagem devido à sua capacidade de manipular uma grande quantidade de informações espaciais, que permitem a identificação de atributos e a análise de questões específicas (Turner \& Gardner 1990).

No Brasil, assim como no estado do Amazonas, o estabelecimento de unidades de conservação é a principal estratégia para evitar a grilagem de terras públicas, ocupação irregular de áreas florestais e a proteção dos elementos bióticos e abióticos das paisagens (Vieira et al. 2005; Bensusan 2006). Neste contexto, a partir de uma demanda das comunidades locais de Manaus, foi criado o Parque Estadual Sumaúma, um dos poucos fragmentos florestais protegidos na área urbana da cidade.
Atualmente, o controle de impactos ambientais em unidades de conservação representa um dos desafios para diversas instituições responsáveis pela gestão de áreas protegidas (Costa \& Silva 2004). Outro aspecto importante é a carência de dados precisos sobre a maioria das unidades de conservação recentemente criadas. O conhecimento dos ecossistemas presentes em áreas protegidas, assim como a sua distribuição espacial é essencial para direcionar seu manejo.

Os objetivos deste estudo consistiram em analisar o Parque Estadual Sumaúma no contexto da ecologia de paisagens e caracterizar a composição florística e estrutural das unidades florestais da área. Espera-se que este estudo possa dar suporte ao plano de gestão e planejamento de ações integradas para a conservação do Parque.

\section{Material e Métodos}

\section{Área de estudo}

O estudo foi realizado no Parque Estadual Sumaúma (PAREST Sumaúma), uma unidade de conservação de proteção integral, criada pelo Decreto Estadual no 23.721 de 05/09/2003 (Bueno \& Ribeiro 2007). O PAREST Sumaúma possui uma área de aproximadamente 52 ha e está localizado entre as coordenadas geográficas $03^{\circ} 01^{\prime} 50^{\prime \prime}$ a $03^{\circ} 2^{\prime} 26^{\prime \prime}$ de latitude Sul e 59 $58^{\prime} 59^{\prime \prime}$ a 59 $58^{\prime} 31^{\prime \prime}$ de longitude Oeste de Greenwich, no bairro Cidade Nova, município de Manaus, AM (Fig. 1). Cidade Nova é o bairro mais populoso da cidade, com cerca de 300.000 habitantes (Amazonas 2009). Este bairro foi planejado para abrigar a população migrante do interior que anteriormente habitava palafitas nos igarapés da cidade. A ocupação do entorno do PAREST começou por volta de 1980 (Gontijo 2008) e, atualmente, a unidade de conservação está completamente isolada em meio a uma matriz urbana (Fig. 1).

O PAREST Sumaúma está inserido em uma região de clima equatorial úmido, com temperatura média anual de $26,7^{\circ} \mathrm{C}$, com temperaturas mínimas de $23,3^{\circ} \mathrm{C}$ e máximas de $31,4^{\circ} \mathrm{C}$. A umidade relativa do ar permanece em torno de $80 \%$ e a média da precipitação anual é de 2.286 mm (Amazonas 2009). A vegetação do PAREST é composta por floresta ombrófila aberta, com predomínio de floresta secundária em diferentes estádios sucessionais. Em alguns locais há vegetação rasteira e, nos vales, floresta de baixio com manchas de palmeiras (Gontijo 2008; Amazonas 2009). Verificase a presença de pequenos mamíferos, destacandose o sauim-de-coleira (Saguinus bicolor Spix), a única espécie ameaçada de extinção entre os Callitrichideos amazônicos (Amazonas 2009). 


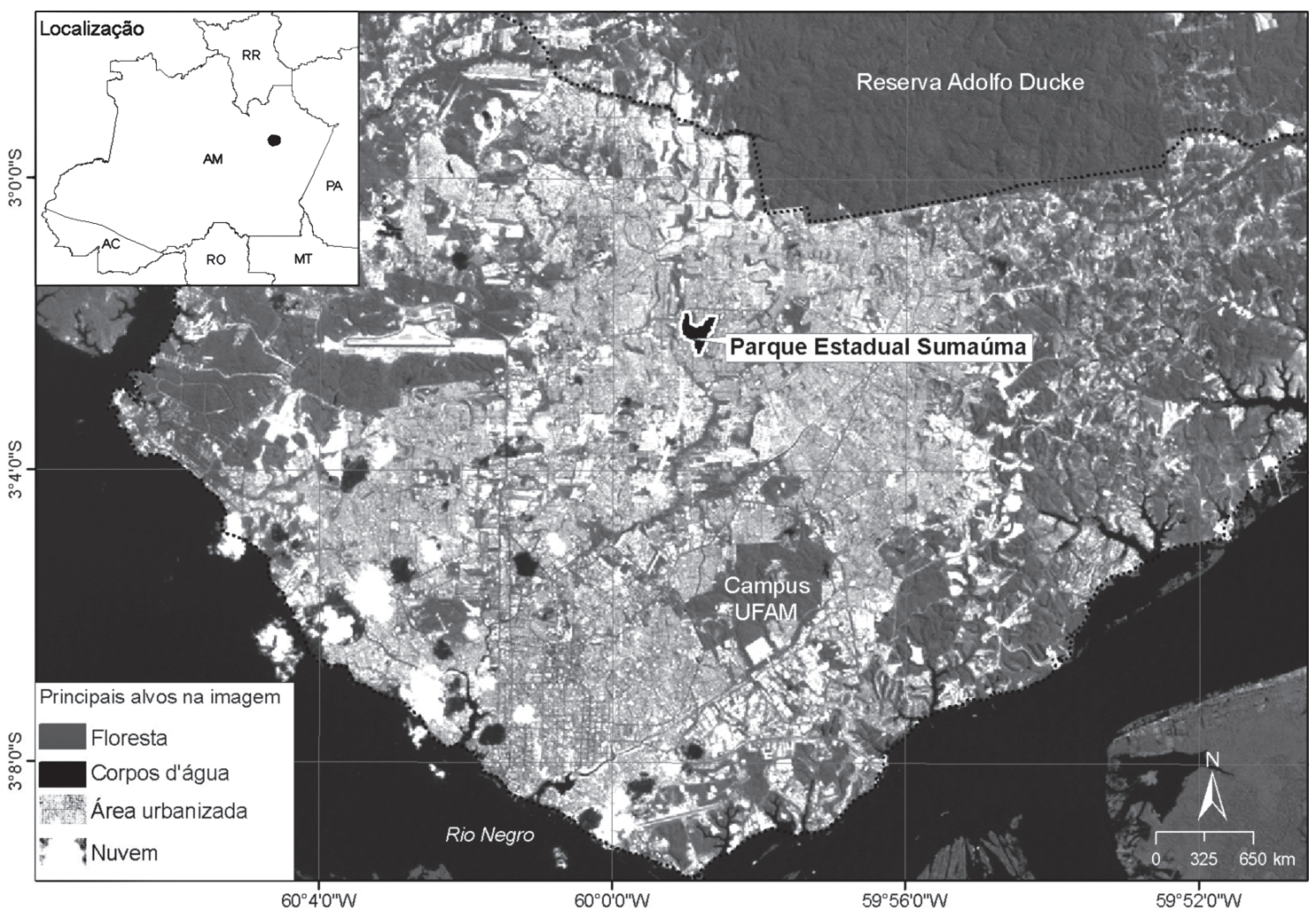

Figura 1 - Localização do PAREST Sumaúma na área urbana de Manaus. Imagem TM/LANDSAT-5, 21/07/2008, banda espectral infravermelho médio $(1,550-1,750 \mu \mathrm{m})$.

Figure 1 - Location of Sumaúma State Park in the urban area of Manaus, Brazil. Image TM/LANDSAT-5, 21/07/2008, mid-infrared spectral band $(1.550-1.750 \mu \mathrm{m})$.

Mapeamento e análise da paisagem

O mapeamento realizado no PAREST Sumaúma consistiu em mapas de relevo (declividades e altimetria), unidades de paisagem e uso e cobertura da terra de seu entorno $(300 \mathrm{~m})$. Para tanto, foram utilizadas uma imagem do satélite QuickBird (adquirida em 17/08/2005, resolução espacial de $0,6 \mathrm{~m}$ ) e base cartográfica em escala 1:10.000 contendo hidrografia, curvas de nível, sistema viário e limite dos bairros (SEMMAS/PMM 2005).

O processamento da imagem QuickBird e as análises dos dados cartográficos foram realizados nos softwares ENVI 4.5 e ArcGIS 9.3.1. Para a obtenção das métricas da paisagem foi empregado o software FRAGSTATS 3.3 (McGarigal et al. 2002). Para a obtenção das coordenadas geográficas em campo foi utilizado um aparelho GPS Garmin CS 76, com precisão nominal de $10 \mathrm{~m}$.

Para análise do relevo do Parque foi gerado um Modelo Digital de Elevação (MDE) a partir da interpolação das curvas de nível, utilizando Rede
Irregular de Triangulação (TIN) e o interpolador linear. A partir do MDE derivaram-se os mapas de declividades, altimetria e perfis topográficos.

As unidades de paisagem foram definidas de acordo com os padrões do relevo da área (declividade e altimetria) e o uso da terra e cobertura vegetal, segundo os métodos propostos por Zonneveld (1989), sendo mapeadas as seguintes classes: floresta de encosta e floresta de baixio, correspondendo segundo IBGE(1992), a floresta ombrófila aberta e floresta ombrófila aberta aluvial, respectivamente; campo antrópico, solo exposto e edificação. O usoe cobertura foram obtidos por técnicas de interpretação visual (Lillesand \& Kiefer 2000). Os critérios utilizados para classificar a vegetação foram os fisionômico-ecológicos, adaptados de IBGE (1992).

Para caracterização da paisagem foram calculadas as seguintes métricas para cada unidade da paisagem (McGarigal et al. 2002; Metzger 2004): área-CA (ha); número de manchas -NP; forma-SHAPE e dimensão fractal -FRAC; área central total - TCA e densidade de borda $-\mathrm{ED}\left(\mathrm{m} \cdot \mathrm{ha}^{-1}\right)$. A área $(\mathrm{CA})$, que quantifica o 
tamanho de cada classe, é a medida de estrutura da paisagem mais difundida e importante, uma vez que é base para outras medidas (Lang \& Blaschke 2009). Segundo Metzger (2004), a forma (SHAPE) dos fragmentos ou manchas da paisagem pode ser avaliada por relações entre área e perímetro ou por índice fractal que medem a complexidade destas formas. Este índice permite estimar a proporção do fragmento submetido aos efeitos de borda. Para o FRAC os valores são distribuídos no intervalo de 1 a 2, sendo que para formas euclidianas simples (círculos e retângulos) o FRAC é igual a 1, para polígonos mais complexos o FRAC tende a 2 (McGarigal et al. 2002). A área nuclear representa o local sem efeito de borda, ou com efeitos mínimos, onde se concentra a maior riqueza do fragmento (Farina 1998). Neste estudo, para análise da densidade de bordas (ED) foi considerado uma distância de $50 \mathrm{~m}$ como a faixa de influência sobre as unidades de paisagem (Murcia 1995). Segundo o autor, após distâncias superiores a $50 \mathrm{~m}$ os efeitos de borda tendem a desaparecer.

\section{Levantamento e análise florística}

Para o levantamento florístico foi efetuada amostragem a partir do método de parcelas (MüllerDombois \& Ellenberg 1974). Foram delimitadas e inventariadas 30 parcelas retangulares de $400 \mathrm{~m}^{2}$, com dimensões de $20 \times 20 \mathrm{~m}$, estabelecidas aleatoriamente, distribuídas nas unidades vegetacionais floresta de encosta e floresta de baixio (Fig. 2). A identificação taxonômica foi realizada em campo por um parataxonomista, baseando-se na observação das flores, folhas, frutos e em caracteres dendrológicos, tais como a casca do tronco (padrão de coloração e cheiro). Foi utilizado o guia de plantas publicado por Ribeiro et al. (1999) como apoio para identificação das espécies. Todos os indivíduos arbóreos com diâmetro a altura do peito (DAP) $\geq 5 \mathrm{~cm}$ foram amostrados. A altura total foi estimada visualmente em campo. As espécies amostradas foram classificadas conforme proposto pelo Angiosperm Phylogeny Group (APG II) (APG 2003). Os nomes botânicos das espécies identificadas foram conferidos com o banco de dados do Missouri Botanical Garden (Tropicos.org 2010). As espécies foram classificadas como exóticas e nativas de acordo com Souza \& Lorenzi (2008) e Ribeiro et al. (1999). As espécies ameaçadas de extinção foram identificadas seguindo a lista da flora ameaçada com ocorrência no Brasil, apresentada pela International Union for Conservation of Nature (IUCN 2005).
Após os levantamentos de campo foram avaliados os parâmetros fitossociológicos (Müeller-Dombois \& Ellenberg 1974), a saber: área basal (G), densidade absoluta (DA) e relativa (DR), frequência absoluta (FA) e relativa (FR), dominância absoluta (DoA) e relativa (DoR), índice de valor de importância (IVI), índice de diversidade de Shannon-Wiener (H') e o índice de equabilidade de Pielou (J'), conforme os métodos compilados por Durigan (2004).

Testes estatísticos foram aplicados para analisar as variáveis: altura média, área basal e do estrato arbóreo das paisagens florestais. Os dados foram submetidos à análise de variância (ANOVA), com nível de significância de 5\%, e aplicado o teste de Tukey para comparação de médias.

\section{Resultados}

\section{Análise da paisagem}

Orelevo do Parque Estadual Sumaúmaé composto por encostas em toda a borda e um vale na parte central. As encostas ocupam aproximadamente $56 \%$ da área do Parque, onde as declividades variam entre $15^{\circ}$ a $45^{\circ}$. No vale, as declividades são menos acentuadas $\left(0^{\circ}\right.$ a $5^{\circ}$ ) ocupando $44 \%$ da unidade de conservação. A altitude média do PAREST é de 71,5 m, as altitudes máximas atingem $90 \mathrm{~m}$ e as mínimas $45 \mathrm{~m}$.

A paisagem do PAREST apresenta, nas áreas com cobertura florestal, dossel de aspecto rugoso com árvores mais altas entremeadas por áreas de regeneração com indivíduos mais baixos e até pequenas clareiras. A vegetação predominante é a floresta secundária em diversos estádios de regeneração. A análise da forma da unidade de conservação resultou em índice de forma médio de 1,55 e a dimensão fractal média de 1,09.

As unidades de paisagem mapeadas no PAREST Sumaúma apresentaram as seguintes características (Fig. 2, Tab. 1), a saber:

Floresta de encosta (floresta ombrófila aberta) representa 53\% do Parque, sendo composta por uma única mancha que ocupa terrenos mais elevados e secos, com índice de forma médio de 1,16 e índice de dimensão fractal médio de 1,01; a densidade de bordas foi a maior $\left(191,92 \mathrm{~m} \cdot \mathrm{ha}^{-1}\right)$ entre as unidades de paisagem mapeadas; a área total do núcleo foi de 3,47 ha.

Floresta de baixio (floresta ombrófila aberta aluvial) ocupa terrenos baixos mais úmidos, sendo composta por uma mancha que ocupa $38 \%$ do PAREST. Os índices de forma médio e de dimensão fractal médio apresentaram valores de 2,26 e 1,22, respectivamente. Esta unidade de paisagem obteve a segunda maior 

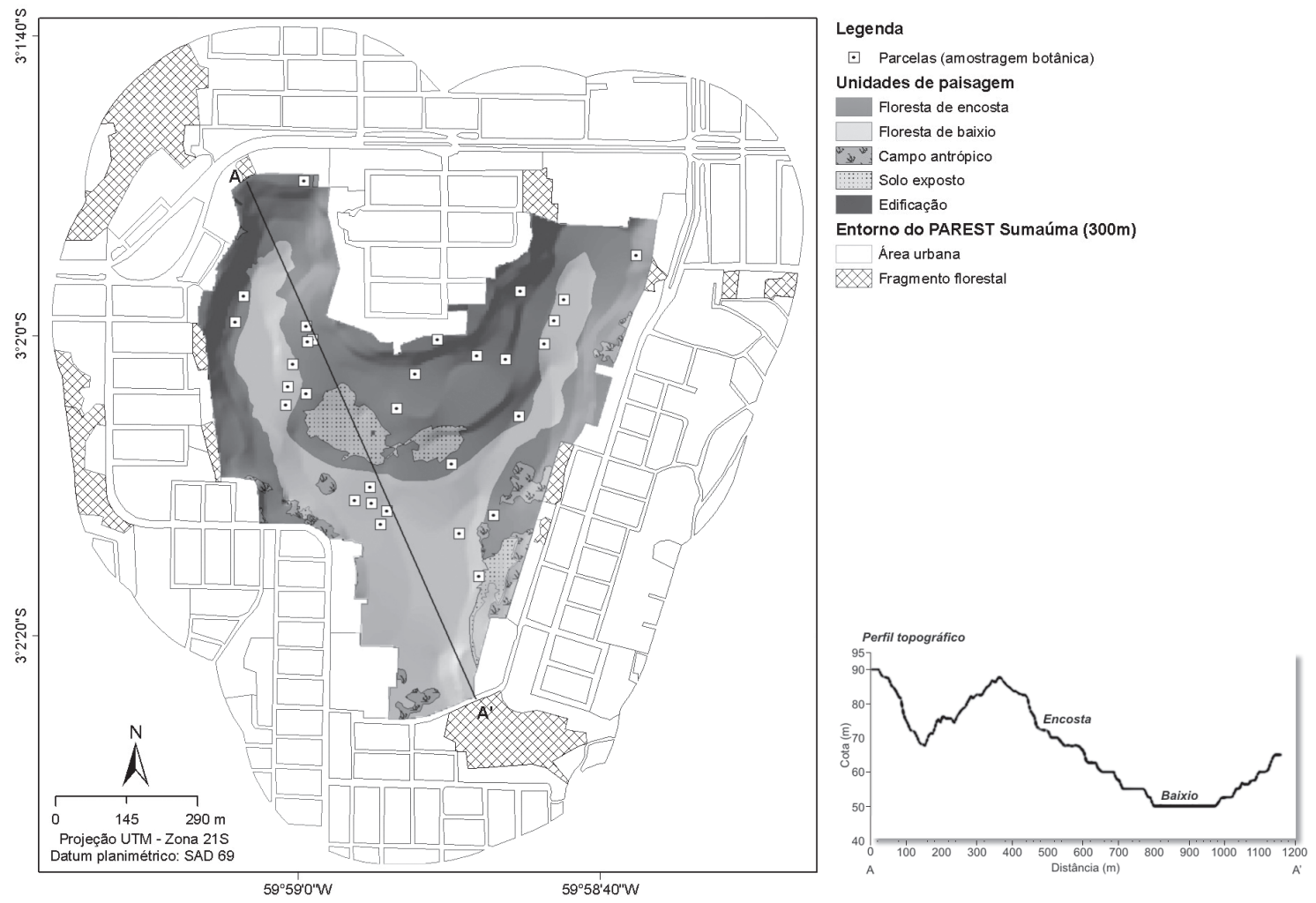

Figura 2 - Unidades de paisagem do PAREST Sumaúma, AM.

Figure 2 - Landscape units of the Sumaúma State Park, AM, Brazil.

densidade de borda 123,66 m.ha ${ }^{-1}$ e a maior área total do núcleo (4,32 ha).

Campo antrópico - constituído por 13 pequenas áreas que representam 3,6\% do Parque, é coberto por gramíneas e arvoretas indicando um processo de regeneração. A densidade de bordas foi de 67,38 $\mathrm{m} \cdot \mathrm{ha}^{-1} \mathrm{e}$ os índices de forma médio e dimensão fractal médio foram de 1,86 e 1,17, respectivamente.

Solo exposto - representado por três manchas que somam 5,62\% do Parque, duas destas localizam-se no centro da unidade de conservação.

Edificações - áreas com construção civil que estão dentro do Parque, representam $0,14 \%$ de sua superfície, entre elas estão o prédio da administração e recepção dos visitantes e um viveiro de mudas.

O mapeamento de uso e cobertura da terra do entorno (300 m) do PAREST Sumaúma permitiu verificar que a área urbanizada (residências e comércios) a partir dos limites da unidade de conservação ocupa 134,65 ha. No entorno da unidade de conservação existem 13 fragmentos florestais com área média de 0,87 ha e área total de 11,36 ha (Fig. 2).

\section{Análise florística e estrutura da florestal}

$\mathrm{O}$ levantamento florístico realizado em uma área amostral de 1,2 ha, ou seja, 2,27\% do PAREST Sumaúma resultou no registro de 1.176 indivíduos, pertencentes a 58 famílias, 134 gêneros e 196 espécies (Anexo 1). As espécies representadas apenas com um indivíduo (raras) somaram 67, correspondendo a $34 \%$ do total observado. Durante o levantamento foram registradas 87 árvores mortas $(7,4 \%$ dos indivíduos amostrados), com 48 na Floresta de encosta e 39 na Floresta de baixio.

As famílias com maior número de espécies amostradas foram: Fabaceae (Caesalpinioideae - 3; Faboideae - 13; Mimosoideae - 2), Arecaceae e Moraceae (11), Mimosaceae (10), Euphorbiaceae (9), Annonaceae (8), Urticacea, Lauraceae e Lecythidaceae (7), Chrysobalanaceae, Melastomataceae, Myristicaceae e Rubiaceae com seis cada uma (Anexo 1). Estas famílias, em conjunto, somaram 39,1\% das espécies amostradas. Os gêneros com maior riqueza florística foram Inga, Swartzia e Pourouma com cinco espécies e Brosimum, Licania, Miconia, Theobroma e 
Tabela 1 - Métricas da paisagem do PAREST Sumaúma, AM, Brasil.

Table 1 - Landscape metrics of the Sumaúma State Park, AM, Brazil.

\begin{tabular}{llcllcc}
\hline Unidade de paisagem & \multicolumn{7}{c}{ Métricas da paisagem } \\
& CA & NP & ED & TCA & SHAPE_MN & FRAC_MN \\
\hline Floresta de encosta & 28,034 & 1 & 191,92 & 3,47 & 1,16 & 1,01 \\
Floresta de baixio & 19,797 & 1 & 123,66 & 4,32 & 2,26 & 1,22 \\
Campo antrópicoo & 1,900 & 13 & 67,38 & 0,0 & 1,86 & 1,17 \\
Solo exposto & 2,966 & 4 & 51,43 & 0,0 & 2,58 & 1,23 \\
Edificações & 0,075 & 3 & 4,21 & 0,0 & 1,26 & 1,08 \\
Total & $\mathbf{5 2 , 7 7 2}$ & & & & & \\
\hline
\end{tabular}

$\mathrm{CA}=$ área da mancha (ha); $\mathrm{NP}=$ número de manchas; $\mathrm{ED}=$ densidade de borda $\left(\mathrm{m}, \mathrm{ha}^{-1}\right)$; $\mathrm{TCA}$ = área total do núcleo (ha), considerando bordas de $50 \mathrm{~m}$; $\mathrm{SHAPE} \mathrm{MN}$ = índice de forma médio; FRAC_MN = índice de dimensão fractal médio.

$\mathrm{CA}=$ Class area $(\mathrm{ha}) ; \mathrm{NP}=$ Number of patches; $\mathrm{ED}=$ Edge density $\left(\mathrm{m}_{\mathrm{h}} \mathrm{ha}^{-1}\right) ; \mathrm{TCA}=$ Total core area (ha), considering edges of $50 \mathrm{~m} ; \mathrm{SHAPE} \_\mathrm{MN}=\mathrm{Mean}$ shape index; FRAC $M N=$ Mean fractal index.

Virola com quatro espécies. Estes gêneros em conjunto somaram $17,8 \%$ das espécies amostradas.

Nas florestas de encosta e baixio, a diversidade florística obtida, segundo o índice de Shannon-Wiener (H') foi de 4,44 e 4,27, respectivamente, e a equabilidade foi de $68,4 \%$ para as duas paisagens florestais.

Analisando-se as dez espécies de maior importância (Fig. 3) é possível verificar que apenas duas foram comuns nas comunidades vegetais (Euterpe oleracea e Phenakospermum guyannense).

Os valores de densidade absoluta considerando o DAP $\geq 5 \mathrm{~cm}$, para a florestas de encosta e baixio foram 1.029,69 ind.ha $^{-1} \mathrm{e}$ 1.046,43 ind.ha ${ }^{-1}$, respectivamente. A área basal na floresta de encosta foi de $23,39 \mathrm{~m}^{2}$.ha-1 e 22,08 $\mathrm{m}^{2} \cdot \mathrm{ha}^{-1}$ na floresta de baixio. Quando considerados apenas os indivíduos com DAP $\geq 10 \mathrm{~cm}$, a densidade apresentou significativa redução: 475,00 ind.ha-1 para a floresta encosta e 594,64 ind.ha ${ }^{-1}$ para floresta de baixio.

A análise da estrutura diamétrica das espécies vegetais indicou que a maior parte dos indivíduos $(86,2 \%)$ possui diâmetros que variam entre 5 e 20 cm (Fig. 4). Nas florestas de encosta e baixio, a altura média dos indivíduos foi de 9,62 $\pm 3,69 \mathrm{~m} \mathrm{e}$ $8,31 \pm 3,39 \mathrm{~m}$, respectivamente. Cerca de $55 \%$ dos indivíduos apresentaram altura entre 5 e $10 \mathrm{~m}$ e $26 \%$ entre 10 e $15 \mathrm{~m}$ (Fig. 5). As espécies emergentes não ultrapassaram 30 metros de altura. Os resultados da ANOVA comprovados pelo teste de Tukey (Tab. 2) indicaram que não há diferença significativa entre a altura média dos indivíduos nas paisagens florestais $(p=0,01)$, havendo, porém, diferença entre a área basal média $(p=0,72)$.

\section{Discussão}

As paisagens do Parque Sumaúma

O PAREST Sumaúma possui uma área de 52,7 ha (Tab. 1), e está isolado em uma paisagem com matriz urbana (Fig. 2), no bairro mais populoso de Manaus ( 300 mil habitantes) (Amazonas 2009).

A criação de corredores ecológicos entre o PAREST e os fragmentos florestais do seu entorno (Fig. 2) seria uma solução para reduzir o isolamento do Parque (Ayres et al. 2005; Lang \& Blaschke 2009), porém as barreiras antrópicas, compostas por ruas com elevado tráfego de veículos e pedestres, dificultam sua realização. O tamanho e o grau de isolamento dos fragmentos florestais são fatores determinantes para a conservação da biodiversidade (McArthur \& Wilson 1967 apud Brown \& Lomolino 2006). A diminuição da superfície dos fragmentos florestais está relacionada à redução exponencial do número de espécies, assim como de suas relações interespecíficas. O isolamento crescente desses fragmentos pode influenciar a queda das taxas de migração e aumento da extinção das espécies isoladas pela crescente pressão urbana (Brown \& Lomolino 2006).

As análises das métricas de forma do PAREST Sumaúma (Tab. 1) indicaram que a unidade de conservação tende para uma forma alongada e complexa (McGarigal et al. 2002). A forma é um parâmetro importante para estudos de fragmentos, uma vez que está relacionada ao efeito de borda. Segundo McGarigal et al. (2002), áreas circulares são desejáveis, já que reduzem a relação borda/ interior, e o centro encontra-se mais protegido por estar menos exposto aos efeitos de borda. Por outro 
lado, fragmentos alongados possuem elevada razão borda/interior e estão mais sujeitos a alterações de borda, impactando a manutenção de determinadas espécies da fauna e flora (Farina 1998). O processo de fragmentação florestal determina alta densidade de bordas na paisagem, o que influencia na composição florística e diversidade de espécies arbóreas (Metzger 2000). Na borda do fragmento pode haver alteração no microclima, devido à maior incidência solar e de vento, além de maior vulnerabilidade ao fogo (Nascimento \& Laurance 2006).

A análise do índice de forma para as unidades de paisagem florestais também indicou a forma alongada e complexa (Tab. 1). Esta forma não-circular sugere a necessidade de maior controle de seus limites (bordas) com a matriz urbana de seu entorno (Figs. 1 e 2). A floresta de encosta apresentou a maior densidade de bordas (Tab. 1) estando mais sujeita aos efeitos do entorno do PAREST. Nesta unidade de paisagem as alterações na vegetação ocorrem principalmente nas bordas de contato com as áreas urbanas, solo exposto e campo antrópico (Fig. 2). Ao longo das trilhas também se observam alterações na floresta, porém com menor intensidade. Por um lado as trilhas facilitam a fiscalização, visitação e atividades de educação ambiental. Por outro permitem que a vegetação sofra o efeito de borda, o que pode provocar a modificação de sua estrutura, substituição por espécies menos tolerantes, redução da matéria orgânica disponível, erosão e compactação dos solos devido ao pisoteio (Murcia 1995), além de possibilitar o livre trânsito de invasores, coletores, entre outros.

$\mathrm{Na}$ floresta de baixio a densidade de bordas (Tab. 1) foi elevada $\left(123,66 \mathrm{~m} \cdot \mathrm{ha}^{-1}\right)$, porém menos impactante, uma vez que na maior parte o contato ocorre com a floresta de encosta. Contudo, ao sul do PAREST as bordas da floresta de baixio fazem fronteira com a área urbana (Fig. 2), mais sujeitas, portanto, a ações predatórias. Na floresta de baixio, principalmente ao longo dos igarapés, observouse a deposição de resíduos sólidos (lixo), carreados através de galerias de águas pluviais das avenidas e ruas que circundam a unidade de conservação. $\mathrm{O}$ despejo de resíduos pode atrair a fauna exótica (cães, gatos, ratos e insetos), além de poluir o solo, as nascentes e propiciar doenças aos visitantes do Parque.

Quanto ao índice área total do núcleo, a floresta de baixio apresentou valores levemente superiores (4,32 ha) quando comparada com a floresta de encosta (3,47 ha) (Tab. 1 e Fig. 2), o que era esperado, uma

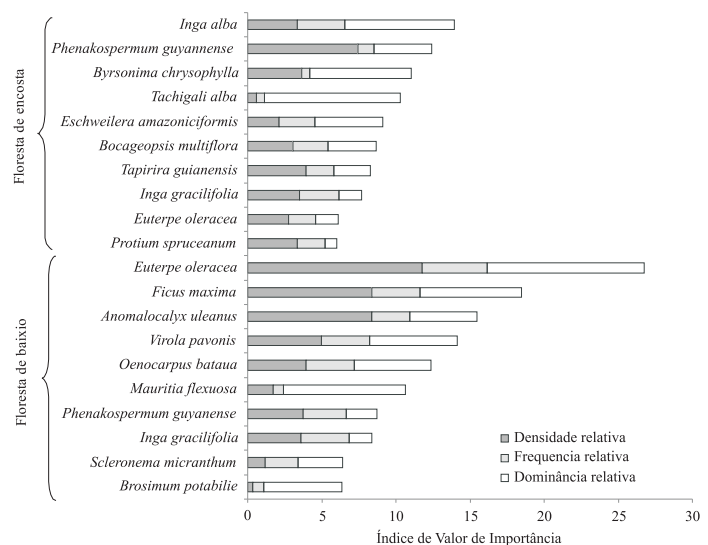

Figura 3 - Parâmetros fitossociológicos das dez espécies com maior IVI, na floresta de encosta e floresta de baixio no PAREST Sumaúma, AM.

Figure 3 - Phytosociological parameters of the ten higher IVI species, by forest phytophysiognomies at Sumaúma State Park, AM, Brazil.

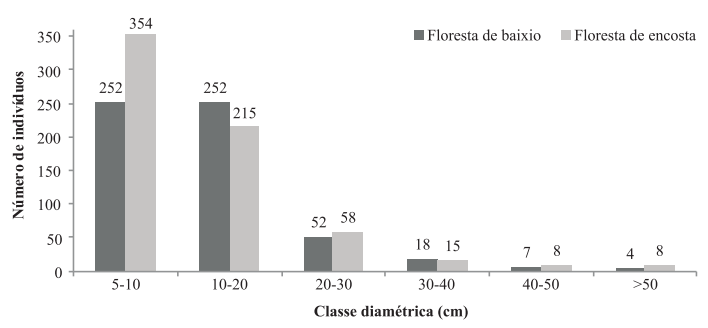

Figura 4 - Distribuição dos indivíduos por classe de diâmetro em dois tipos florestais no PAREST Sumaúma, AM.

Figure 4 - Individuals distribution by classes of diameter $(\mathrm{cm})$ in two forest types at Sumaúma State Park, AM, Brazil.

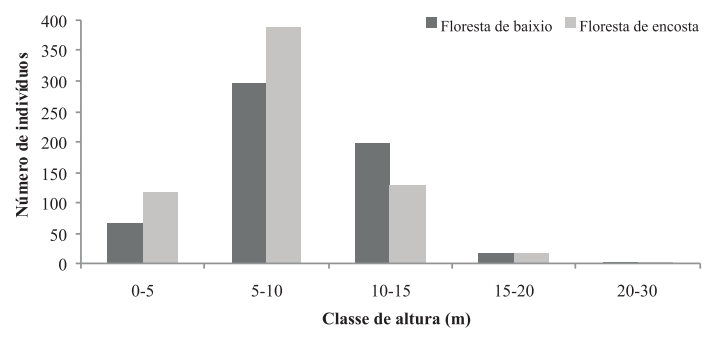

Figura 5-Distribuição dos indivíduos por classe de altura em dois tipos florestais no PAREST Sumaúma, AM.

Figure 5 - Individuals distribution by classes of height $(\mathrm{m})$ in two forest types at Sumaúma State Park, AM, Brazil. 
Tabela 2 - Análise de variância $(p=0,05)$ para as variáveis altura média e área basal da floresta de encosta e floresta de baixio no Parque Estadual Sumaúma, Manaus, AM.

Table 2 - Analysis of variance $(p=0.05)$ for the variables average height and basal area of slope and lowland forests in the Sumaúma State Park, AM.

\begin{tabular}{lllllll}
\hline Altura média $(\mathbf{h m})$ & \multicolumn{1}{l}{ ( } & & & & & \\
\hline Fonte da variação & SQ & gl & F & valor-P & Fc \\
Hm & 8,74 & 1 & 8,74 & 7,87 & 0,01 & 4,20 \\
Resíduos & 31,07 & 28 & 1,11 & & & \\
Total & 39,81 & 29 & & & & \\
\hline
\end{tabular}

\begin{tabular}{lllllll}
\hline Área basal $(\mathbf{G})\left(\mathbf{m}^{\mathbf{2}} \cdot \mathbf{h a}^{\mathbf{- 1}}\right)$ & \multicolumn{1}{l}{} \\
\hline Fonte da variação & SQ & $\mathrm{gl}$ & MQ & F & valor-P & Fc \\
G & 12,75 & 1 & 12,75 & 0,13 & 0,72 & 4,19 \\
Resíduos & 2700,92 & 28 & 96,46 & & & \\
Total & 2713,673 & 29 & & & & \\
\hline
\end{tabular}

$S Q$ : Soma de quadrados; $g l$ : Graus de liberdade; $Q M$ : Quadrado médio; $F c$ : $\mathrm{F}$ crítico.

$S Q$ : Sum of squares; $g l$ : Degrees of freedom; $Q M$ : Mean Square; $F c$ : $\mathrm{F}$ critical.

vez que a floresta de encosta possui valores maiores para densidade de bordas (Tab. 1). Na floresta de baixio ocorre grande quantidade de palmeiras, muitas das quais fornecem alimento para os animais. Esta unidade de paisagem evoca maior preocupação no que tange a sua conservação.

\section{A floresta do Parque Sumaúma}

As paisagens florestais do PAREST sofreram diferentes tipos e graus de impactos ambientais, anteriores a criação da unidade de conservação (Bueno \& Ribeiro 2007). Contudo os valores observados no levantamento florístico foram próximos aos encontrados por outras pesquisas realizadas na Floresta Amazônica(Oliveira et al.2008; Espírito-Santo et al. 2005; Oliveira \& Amaral 2004).

No PAREST Sumaúma 67 espécies foram registradas com um único indivíduo (Anexo 1), o que representa um número menor de espécies raras em comparação com outros estudos em áreas de floresta tropical, Oliveira \& Amaral (2004) encontram 105 e Oliveira et al. (2008) 120. Este resultado pode estar associado às alterações antrópicas que a vegetação da unidade de conservação sofreu ao longo do tempo, ou a processos biológicos intrínsecos à biologia reprodutiva das espécies e sua regeneração em condição de fragmento pequeno e isolado. A semelhança em riqueza florística com áreas de floresta não perturbada é indício de que a menor proporção de espécies "raras", ou de baixa densidade, não indica que outras espécies deste grupo tenham sido extintas. Para Muniz et al. (1994), as florestas do Bioma Amazônico são representadas por poucas espécies abundantes e muitas espécies raras.

A família Fabaceae apresentou maior ocorrência na área de estudo. Esta família possui ampla distribuição na Amazônia, com amplo número de espécies arbóreas na Reserva Adolfo Ducke (Ribeiro et al. 1999), uma área próxima $2,8 \mathrm{~km}$ do PAREST (Fig. 1). É importante destacar o grande número de espécies da família Arecaceae (palmeiras), uma vez que segundo Nelson \& Oliveira (2001), são mais comuns em áreas de florestas de transição ou em áreas perturbadas.

A análise da diversidade florística a partir do índice de Shannon-Wiener para Florestas de encosta e baixio indicou uma alta diversidade florística $(4,44$ e 4,27, respectivamente), e equabilidade (uniformidade) moderada $(\sim 70 \%)$. Oliveira et al. (2008) ao analisarem um hectare de floresta primária obtiveram valor de 5,10. Espirito-Santo et al. (2005) obtiveram índice de diversidade igual a 4,44 para floresta primária e 4,09 para floresta secundária. Muniz et al. (1994) na Reserva florestal de Sacavém (MA) encontraram uma diversidade de 4,19. Uma explicação para a diversidade encontrada no PAREST pode estar associada à característica de diversos estádios sucessionais. Conforme Espírito-Santo et al. (2005), o elevado número de estádios resulta em maior 
diversidade florística. Além disso, na floresta de encosta vários locais são utilizados por moradores como pomar onde espécies foram introduzidas, o que pode alterar os valores encontrados para a diversidade florística. Outro aspecto importante para comparação de valores de diversidade está associado à amostragem. Segundo Martins \& Santos (1999), o índice de Shannon-Wiener é sensível ao critério de inclusão, uma vez que incorpora os efeitos de variações quanto ao número de indivíduos e espécies amostradas.

As espécies mais importantes, segundo o IVI (Fig. 3), foram distintas daquelas encontradas em diferentes estudos na Floresta Amazônica. Ribeiro et al. (1994) para a Reserva Adolfo Ducke descreveram Dinizia excelsa, Oenocarpus bacaba, Astrocaryum sciophilum e Eischweilera amazoniciformis. Oliveira \& Amaral (2004) encontram Eischweilera bracteosa, Protium apiculatum, Pouteria filipes, Eischweilera tessmannii e Licania octandra entre as mais importantes. Segundo Muniz et al. (1994), o índice de valor de importância apresenta valores relativos, dependentes do tamanho, forma e número de parcelas, não sendo adequado a comparação com diferentes metodologias. As florestas da Amazônia possuem uma flora muito rica, algumas espécies têm densidade e dominância baixa e variada o que torna a obtenção de estimativas da importância relativa quase impossível (Muniz et al. 1994). Contudo, para Oliveira \& Amaral (2004), o IVI pode ser empregado como indicador da importância ecológica, devido à influência das espécies mais frequentes e dominantes nos processos básicos de equilíbrio da flora.

$\mathrm{Na}$ Floresta de encosta as espécies mais importantes (Fig. 3), portanto ecologicamente dominantes no local, foram Inga alba (ingá-vermelho), Phenakospermum guyannense (sororoca) e Byrsonima chrysophylla (murici). P. guyannense foi a segunda espécie mais importante, com densidade relativa de $7,4 \%$, quase o dobro da densidade na Floresta de baixio (3,8\%) (Fig. 3). Segundo IBGE (1992), $P$. guyannense é uma espécie típica da floresta ombrófila aberta, ocorre nas depressões temporariamente inundadas e rasas, podendo ser observada também em relevos ondulados e sobre Latossolos. A espécie forma grandes populações em áreas alteradas (Ribeiro et al. 1999), como observado no PAREST. A presença do B. chrysophylla e Tapirira guianensis entre as espécies mais importantes (Fig. 3) é um indicativo das alterações que o PAREST sofreu antes de sua criação, uma vez que estas espécies são pioneiras. $B$. chrysophylla é uma espécie pioneira típica da
Amazônia, ocorrendo em diversas partes do bioma (Ribeiro et al. 1999). T. guianensis é uma espécie arbórea perenifólia, pioneira, heliófita e de ampla distribuição pelo Brasil.

Na floresta de baixio, Euterpe oleracea (açaí), Ficus maxima (gameleira) e Anomalocalyx uleanus (arataciú-preto) foram as espécies mais importantes. Além destas, destacam-se as palmeiras Oenocarpus bataua e Mauritia flexuosa (Fig. 3). Para Ribeiro et al. (1999), estas palmeiras são típicas deste ambiente úmido, ainda que também sejam indicativas de áreas perturbadas (Nelson \& Oliveira 2001). E.oleracea apresentou altos valores de densidade e dominância relativa (Fig. 3). Esta palmeira ocorre principalmente na Amazônia Oriental (Miranda \& Rabelo 2006) em áreas alagadas do delta do Amazonas (no Pará e Amapá). E. oleracea também foi observada nas encostas íngremes no PAREST, cultivada nos quintais das residências do entorno da unidade de conservação. Os frutos desta espécie são bastante consumidos e dispersos por pássaros (Miranda \& Rabelo 2006).

A análise dos parâmetros estruturais da vegetação (densidade, área basal e distribuição dos indivíduos por classes de tamanho) indicou que há poucos indivíduos com alta densidade. Os valores de área basal foram próximos aos encontrados em estudos na Amazônia e a maior parte das árvores tem diâmetros pequenos e possui altura de até $10 \mathrm{~m}$.

A densidade de indivíduos (abundância) no PAREST, considerando o DAP $\geq 5 \mathrm{~cm}$, foi maior do que a encontrada em outros estudos na Amazônia Central. Considerando o DAP $\geq 10 \mathrm{~cm}$ a densidade apresentou significativa redução, principalmente na floresta de encosta, com valores inferiores aos descritos por Oliveira et al. (2008) 670 ind.ha-1, $^{-1}$ Oliveira \& Amaral (2004) 771 ind.ha ${ }^{-1}$ e próximos aos observados por Ivanauskas et al (2004), no estrato superior da floresta (546 ind.ha ${ }^{-1}$ ).

Os valores encontrados para área basal florestas de encosta e baixio 23,39 $\mathrm{m}^{2}$.ha $\mathrm{h}^{-1}$ e 22,08 $\mathrm{m}^{2} \cdot \mathrm{ha}^{-1}$, respectivamente, foram próximos aos observados em outros estudos na Amazônia brasileira, de acordo com dados citados por Higuchi \& Santos (2004), em levantamentos realizados em Projetos de Integração e Colonização (PIC) em Altamira/PA $\left(21,97 \mathrm{~m}^{2} \cdot \mathrm{ha}^{-1}\right)$, na Estação Experimental de Silvicultura Tropical/AM $\left(22,74 \mathrm{~m}^{2}\right.$.ha-1) e próximo à Usina Hidrelétrica de Balbina/AM (29,38 $\left.\mathrm{m}^{2} \cdot \mathrm{ha}^{-1}\right)$. Muniz et al. (1994) obtiveram 28,41 m².ha-1 no Maranhão.

A distribuição dos indivíduos por classe de diâmetro (Fig. 4) seguiu um formato de J invertido, com muitos indivíduos de pequeno diâmetro e 
poucos indivíduos com diâmetro elevado. Esta característica permite inferir que a floresta passa por um processo de regeneração, ainda que ocorra uma dinâmica de mortalidade e recrutamento de novos indivíduos na comunidade (Braga et al. 2007). As espécies que foram consideradas de grande porte com DAP acima de $50 \mathrm{~cm}$ foram representadas por poucos indivíduos. Na floresta de encosta é possível citar Tachigali alba (tachi-branco) com dois indivíduos de DAP igual a 72,57 cm e 105,14 $\mathrm{cm}$, Byrsonima chrysophylla (murici) com um indivíduo com 100,5 cm de DAP e Brosimum parinarioides (amapá-garrote) com um indivíduo com 76,4 cm de diâmetro. Na floresta de baixio os maiores DAPs foram registrados nas seguintes espécies: Brosimum potabilie (pau-rainha) $(90,7$ $\mathrm{cm})$, Aldina heterophylla (macucu do baixio) $(57,30$ $\mathrm{cm})$ e Swartzia reticulata (arabá-preto) $(57,50 \mathrm{~cm})$.

De modo geral, as árvores no PAREST possuem estatura baixa (Fig. 5). As emergentes raramente atingem $30 \mathrm{~m}$ de altura e são representadas por poucos indivíduos. Na floresta de encosta observam-se Brosimum parinarioides (amapá-garrote) com $28 \mathrm{~m}$ de altura, Vismia guianensis (lacre-branco) e Couratari guianensis (tauri-branco) com $25 \mathrm{~m}$, todos com apenas um indivíduo amostrado. Na floresta de baixio os maiores indivíduos foram Brosimum potabilie (pau-rainha) com $26 \mathrm{~m}$, Aldina heterophylla (macucu-do-baixio) com 25 m e a Hevea guianensis (seringueira-vermelha) com $25 \mathrm{~m}$.

Diversos moradores do entorno realizam plantios na área do PAREST, sendo observadas espécies vegetais exóticas e nativas. Entre as exóticas foram encontradas Mangifera indica (mangueira), Artocarpus altilis (fruta-pão) e Averrhoa carambola (carambola). As principais espécies nativas identificadas foram Euterpe oleracea (açaí), Bactris gassipaes (pupunha), Persea americana (abacate), Spondias mombin (taperebá), Rollinia mucosa (biribá), Theobroma cacao (cacau), Inga edulis (ingá), Bixa orellana (urucum). Além destas espécies, durante as expedições na área também foram observadas Artocarpus heterophyllus (jaqueira), bananeiras e coqueiros.

De modo geral, o cultivo destas espécies é importante para o PAREST, uma vez que são espécies frutíferas que servem de alimento para a fauna e fontes de polinização. S. mombin, por exemplo, é considerada de grande importância na recuperação de vegetação degradada, pela sua rusticidade, rapidez de crescimento e disseminação, além de atração para a fauna (Instituto Hórus 2010). Entretanto, espécies exóticas como $M$. indica geram alteração do pH de cursos d'água, devido ao apodrecimento das folhas e frutos em grande quantidade. A. heterophyllus ocupa áreas na floresta substituindo a vegetação nativa, reduzindo o hábitat para flora e fauna (Instituto Hórus 2010).

NoPAREST, segundo Gontijo (2008), há outros problemas ambientais, como a extração clandestina de produtos não-madeireiros (açaí, buriti, patauá, tucumã, palha), madeira, caça de pequenos mamíferos (p.ex., cutia e tatu) e a pesca. Os cursos d'água, ainda que poluídos, são utilizados para recreação (banhos).

Estes efeitos de vizinhança podem ser minimizados ou mesmo benéficos, a partir da aplicação de programas de educação ambiental, por meio de atividades inclusivas, o que facilitaria o cumprimento da função social do PAREST ao contribuir para o fortalecimento do vínculo entre a comunidade e a unidade de conservação, bem como para a minimização dos impactos diretos decorrentes dessa proximidade. Estes programas de educação, entre outros objetivos, devem orientar os moradores quanto às espécies mais indicadas para o plantio em seus quintais e evitar plantios dentro dos limites do Parque.

Entre as espécies encontradas neste estudo, seis são consideradas ameaçadas de extinção de acordo com IUCN (2005), a saber: Aspidosperma polyneuron (pau-caboclo), Bowdichia nitida (sucupira-preta), Couratari guianensis (tauari branco), Eschweilera amazoniciformis (matamatá), Sorocea guilleminiana (matacalada), Micropholis casiquiarensis (abiurana). O estabelecimento deste fragmento florestal urbano como área protegida é de extrema importância. Ainda que esteja alterado, a área mantém uma parte da flora primitiva que cobria a região. $\mathrm{O}$ fragmento pode servir como fonte de sementes para programas de reflorestamento e recuperação de áreas degradadas.

O estudo de ecologia da paisagem associado à análise florística pode auxiliar no planejamento e suporte a decisões aplicadas à gestão de áreas protegidas, uma vez que a vegetação pode ser considerada como um indicador das condições ambientais de uma área (Lang \& Blaschke 2009). As métricas da paisagem revelaram que a floresta de encosta está mais sujeita aos efeitos de borda, embora a parte sul da floresta de baixio também seja impactada. Os efeitos de borda podem alterar a composição florística e a distribuição de espécies vegetais em uma paisagem florestal (Herrmann $e t$ al. 2005; Nascimento \& Laurance 2006; Lang \& Blaschke 2009). A composição florística e a estrutura das paisagens florestais no PAREST apresentaram 
alta diversidade, mas com características de vegetação secundária. Contudo, esta mancha remanescente de Floresta Amazônica contém diversos exemplares nativos e alguns ameaçados de extinção, serve de refúgio para a fauna, além de ser uma opção de lazer e bem estar para a população. Por esse motivo, é necessário preservar e manejar adequadamente áreas de fragmentos florestais urbanos, bem como realizar estudos permanentes, tendo em vista um manejo orientado para que a regeneração de áreas alteradas seja o mais próximo possível dos ambientes florestais menos impactados.

\section{Agradecimentos}

Nossos agradecimentos ao Sr. Pedro Marinho de Carvalho, o auxílio no reconhecimento botânico, e aos estudantes Heitor Paulo Pinheiro, Ronam de Souza Gato e Wendell Adriano F. Aquino, o suporte oferecido durante os levantamentos. Este trabalho teve apoio financeiro do Conselho Nacional do Desenvolvimento Científico e Tecnológico - CNPq (Processo 473603/2008).

\section{Referências}

Amazonas. 2009. Parque Estadual Sumaúma. Secretaria de Estado de Meio Ambiente e Desenvolvimento Sustentável Manaus: SDS. Série técnica planos de gestão, Manaus. 169p.

Angiosperm Phylogeny Group (APG). 2003. An update of the angiosperm phylogeny group classication for the orders and families of flowering plants: APG II. Botanical Journal of the Linnean Society 141: 399-436.

Ayres, J.M.; Fonseca, G.A.B.; Rylands, A.B.; Queiroz, H.L.; Pinto, L.P.; Masterson, D. \& Cavalcanti, R.B. 2005. Os corredores ecológicos das florestas tropicais do Brasil. Sociedade Civil Mamirauá, Belém. 256p.

Bensusan, N. 2006. Conservação da biodiversidade em áreas protegidas. Ed. FGV, Rio de Janeiro. 176p.

Bononi, V.L.R. 2004. Controle ambiental de áreas verdes. In: Philippi Jr, A.; Romério, M.A. \& Bruna, G.C. (eds.). Curso de gestão ambiental. Coleção Ambiental. Manoele, Barueri. Pp. 213-255.

Braga, P.I.S.; Silva, S.M.G.; Braga, J.O.N.; Nascimento, K.G.S. \& Rabelo, S.L. 2007. A vegetação das comunidades da área de influência do projeto Piatam e do gasoduto Coari-Manaus. EDUA, Manaus. 160p.

Brown, J.H. \& Lomolino, M.V. 2006. Biogeografia. $2 a$ ed. FUNPEC Editora, Ribeirão Preto. 691p.

Bueno, N.P.E. \& Ribeiro, K.C.C. 2007. Unidades de Conservação - caracterização e relevância social, econômica e ambiental: um estudo acerca do Parque Estadual Sumaúma. Revista Eletrônica Aboré1-14.
Costa, L.A.; Alves, J.L.; Bühring. R.; Batista, M.A.A. \& Tello, J.C.R. 2008. Uso de sistema de informações geográficas (SIG) como apoio ao estudo de florestas urbanas na cidade de Manaus, Amazonas. In: Anais do VIII Seminário de Atualização em Sensoriamento Remoto e Sistemas de Informações Geográficas Aplicados à Engenharia Florestal, Curitiba. Pp. 241-247.

Costa, N.M.C. \& Silva, J.X. 2004. Geoprocessamento aplicado à criação de planos de manejo: o caso do Parque Estadual da Pedra Branca, RJ. In: Silva, J.X. \& Zaidan, R.T. (eds.). Geoprocessamento \& análise ambiental: aplicações. Bertrand Brasil, Rio de Janeiro. Pp. 67-114.

Durigan, G. 2004. Métodos para análise de vegetação arbórea. In: Cullen Jr., L.; Rudran, R. \& PaduaValladares, C. (eds.). Métodos de estudos em biologia da conservação e manejo da vida silvestre. Ed. da UFPR; Fundação O Boticário de Proteção à Natureza, Curitiba. Pp. 455-479.

Espírito-Santo, F.D.B.; Shimabucuro, Y.E.; Aragão, L.E.O.C. \& Machado, E.L.M. 2005 Análise da composição florística e fitossociológica da floresta nacional do Tapajós com apoio geográfico de imagens de satélites. Acta Amazonica 35: 155-173.

Farina, A. 1998. Principles and methods in landscape ecology. Chapman \& Hall Ltd., London. 224p.

Gascon, C.; Laurance, W.F. \& Lovejoy, T.E. 2002. Fragmentação florestal e biodiversidade na Amazônia central. In: Souza Dias, B.F. \& Garay, I. (eds.). Conservação da biodiversidade em ecossistemas tropicais: avanços conceituais e revisão de novas metodologias de avaliação e monitoramento. Ed. Vozes, Petrópolis. Pp. 112-127.

Gontijo, J.C.F. 2008. Uso e característica dos fragmentos florestais urbanos da cidade de Manaus, AM. Dissertação de Mestrado. Universidade Federal do Amazonas, Amazonas. 95p.

Herrmann, B.C.; Efraim Rodrigues, E. \& Lima, A. 2005. A paisagem como condicionadora de bordas de fragmentos florestais. Floresta 35: 13-22.

Higuchi, N. \& Santos, J. 2004. Inventário florestal (volume, biomassa fresca acima do nível do solo e carbono) da Fazenda São Francisco localizada no município de Manacapuru. Instituto Nacional de Pesquisas da Amazônia (INPA). Relatório técnico. 76p.

Instituto Hórus. 2010. Base de dados I3N de espécies exóticas e invasoras. Disponível em <http://www. institutohorus. org.br>. Acesso em 04 junho 2010.

IBGE - Instituto Brasileiro de Geografia e Estatística. 1992. Manual técnico da vegetação brasileira. Manuais Técnicos em Geociências, n. 1, Rio de Janeiro. 92p.

INPE - Instituto Nacional de Pesquisas Espaciais. 2009. Projetos e atividades. (Monitoramento da floresta amazônica brasileira por satélite - PRODES; Detecção de desmatamento em tempo real DETER). Disponível em <http://www.dsr.inpe.br/ projetos.htm>. Acesso em 01 outubro 2009. 
IUCN - International Union for Conservation of Nature. 2005. Revisão da lista da flora brasileira ameaçada de extinção. Disponível em <http://www.biodiversitas. org.br/floraBr/iucn.pdf>. Acesso em 03 junho 2010.

Ivanauskas, N.M.; Monteiro, R. \& Rodrigues, R.R. 2004. Estrutura de um trecho de Floresta Amazônica na bacia do alto rio Xingu. Acta Amazonica 34: 275-299.

Lang, S. \& Blaschke, T. 2009. Análise da paisagem com SIG. Oficina de Textos, São Paulo. 424p.

Laurance, W.F.; Cochrane, M.A.; Bergen, S.; Fearnside, P.M.; Delamônica, P.; Barber, C.; D’Angelo, S. \& Fernandes, T. 2001. The future of the Brazilian Amazon. Science, 291: 438-439.

Lillesand, T.M. \& Kiefer, R.W. 2000. Remote sensing and image interpretation. 4ed. John Wiley \& Sons, New York. 721p.

Martins, F.R. \& Santos, F.A.M. 1999. Técnicas usuais de estimativa da biodiversidade. Revista Holos 1: 236-267.

McGarigal, K.; Cushman, S.A.; Neel, M.C. \& Ene, E. 2002. Fragstats: Spatial Pattern Analysis Program for Categorical Maps. Computer software program produced by the authors at the University of Massachusetts, Amherst. Disponível em <http:// www.umass.edu/landeco/research/fragstats/ fragstats.html>. Acesso em 01 outubro 2009.

Metzger, J.P. 2000. Tree functional group richness and landscape structure in Brazilian tropical fragmented landscape. Ecological Applications 10: 1147-1161.

Metzger, J.P. 2002. O que é ecologia de paisagens? Biota Neotropica 1: 1-9.

Metzger, J.P. 2004. Estrutura da paisagem: o uso adequado de métricas. In: Cullen Jr., L.; Rudran, R. \& Padua-Valladares, C. (eds.). Métodos de estudos em biologia da conservação e manejo da vida silvestre. Ed. da UFPR; Fundação O Boticário de Proteção à Natureza, Curitiba, PR. Pp. 423-453.

Miranda, I.P.A. \& Rabelo, A. 2006. Guia de identificação das palmeiras de um fragmento florestal urbano. Manaus: EDUA/INPA. 228p.

Müller-Dombois, D. \& Ellenberg, H. 1974. Aims and methods in vegetation ecology. John Wiley \& Sons, New York. 547p.

Muniz, F.H.; Cesar, O. \& Monteiro, R. 1994. Fitossociologia da vegetação arbórea da Reserva florestal do Sacavém, São Luís, Maranhão (Brasil). Acta Amazonica 24: 219-236.

Murcia, C. 1995. Edge effects in fragmented forests: implications for conservation. Tree 10: 58-62.

Nascimento, H.E.M. \& Laurance, W.F. 2006. Efeitos de área e de borda sobre a estrutura florestal em fragmentos de floresta de terra-firme após 13-17 anos de isolamento. Acta Amazonica 36: 183-192.
Nelson, B.W. \& Oliveira, A. 2001. Estado do conhecimento florístico da Amazônia. In: Capobianco, J.P.R. Veríssimo, A.; Moreira, A.; Sanwyer, D.; Santos, I. \& Pinto, L.P. (eds.). Biodiversidade na Amazônia brasileira: avaliação e ações prioritárias para a conservação, uso sustentável e repartição de benefícios. (Documentos temáticos). São Paulo. Pp. 132-182.

Oliveira, A.N. \& Amaral, I.L. 2004. Florística e fitossociologia de uma floresta de vertente na Amazônia Central, Amazonas, Brasil. Acta Amazonica 34: 21-34.

Oliveira, A.N.; Amaral, I.L.; Ramos, M.B.P.; Nobre, A.D.; Couto, L.B. \& Sahdo, R.M. 2008. Composição e diversidade florístico-estrutural de um hectare de floresta densa de terra firme na Amazônia Central, Amazonas, Brasil. Acta Amazonica 38: 627-642.

Ribeiro, J.E.L.S, Hopkins, M.J.G.; Vicentini, A.; Sothers, C.A.; Costa, M.A.S.; Brito, J.M.; Souza, M.A.D.; Martins, L.H.P.; Lohmann, L.G.; Assunção, P.A.C.L.; Pereira, E.C.; Silva, C.F.; Mesquita, M.R. \& Procópio, L.C. 1999. Flora da Reserva Ducke. Guia de identificação das plantas vasculares de uma floresta de terra-firme na Amazônia Central, Instituto Nacional de Pesquisas da Amazônia, Manaus. 793p.

Ribeiro, J.E.L.S.; Nelson, B.W.; Silva, M.F.; Martins, L.S.S. \& Hopkins, M.J.G.1994. Reserva Florestal Ducke: diversidade e composição da flora vascular. Acta Amazônica, 24: 19-30.

Rovere, A.L.N. \& Crespo, S.S. 2002. Projeto GeoCidade: Relatório urbano ambiental integrado. Informe Geo-Manaus. Coord. Veloso, R. Consórcio parceria 21. 188p.

SEMMAS/PMM - Secretaria Municipal de Meio Ambiente e Sustentabilidade - Prefeitura Municipal de Manaus. 2005. Base cartográfica. Escala: 1:10.000.

Souza, V.C. \& Lorenzi, H. 2008. Botânica sistemática: guia ilustrado para identificação das famílias de fanerógamas nativas e exóticas no Brasil, baseado em APG II. Instituto Plantarum, Nova Odessa. 704p.

Tropicos.org. 2009. Missouri Botanical Garden. Disponível em <http://www.tropicos.org $>$. Acesso em 10 dezembro 2009.

Turner, M.G. \& Gardner, R.H. 1990. Quantitative methods in landscape ecology: an introduction. In: Turner, M.G. \& Gardner, R.T. (eds.). Quantitative methods in landscape ecology: the analysis and interpretation of landscape heterogeneity. SpringerVerlag, New York. Pp. 3-12.

Vieira, I.C.G.; Silva, J.M.C. \& Toledo, P.M. 2005. Estratégias para evitar a perda de biodiversidade na Amazônia. Estudos Avançados 19: 153-164.

Zonneveld, I. 1989. The land unit - A fundamental concept in landscape ecology, and its applications. Landscape ecology 3: 67-86. 
Anexo 1 - Espécies registradas nas unidades de paisagem florestais do PAREST Sumaúma, AM

Annex 1 - Registered species in forest landscape units of the Sumaúma State Park, AM, Brazil

\begin{tabular}{lcc}
\hline Família/Espécie & Nome popular & $\mathbf{N}^{0}$ de indivíduos amostrados \\
& F. Baixio F. Encosta Total
\end{tabular}

Anacardiaceae

Mangifera indica $\mathrm{L}$.

mangueira

tapereba

Spondias mombin L.

pau-pombo

4

1

3

1

Tapirira guianensis Aubl.

11

$26 \quad 37$

\section{Annonaceae}

Bocageopsis multiflora (Mart.) R.E.Fr.

Fusaea longifolia (Aubl.) Saff.

Guatteria citriodora Ducke

Guatteria olivacea R.E.Fr.

Rollinia insignis R.E.Fr.

Rollinia mucosa (Jacq.) Baill.

Xylopia amazonica R.E.Fr.

Xylopia benthamii R.E.Fr.

envira-preta
envira-surucucu
envira-amarela
envira-bobó
biribá bravo
biribá
envira-vermelha
envira-pacovi

$\begin{array}{lll}14 & 20 & 34 \\ 3 & 5 & 8 \\ 2 & 1 & 3 \\ 6 & 11 & 17 \\ 2 & & 2 \\ & 3 & 3 \\ 1 & 1 & 2 \\ & 1 & 1\end{array}$

\section{Apocynaceae}

Aspidosperma desmanthum Benth. ex Müll.Arg Aspidosperma polyneuron Müll. Arg.

piquiá-marfim

pau-caboclo

Couma guianensis Aubl.

sorva-grande

sorva

acariquara-branca

cumaí

morototó

Schefflera morototoni (Aubl.)

Maguire, Steyerm. \& Frodin

\section{Arecaceae}

Astrocaryum aculeatum G. Mey.

tucumã

$3 \quad 3$

Bactris gasipaes Kunth

pupunha

Euterpe oleracea Mart.

Euterpe precatoria Mart.

açaí

$3 \quad 3$

Iriartella stenocarpa Burret

açaí-da-mata

69

$\begin{array}{ll}18 & 87\end{array}$

Mauritia aculeata Kunth

Mauritia flexuosa L.f.

paxiúbarana

$16 \quad 19$

buritirana

22

Oenocarpus bacaba Mart.

Oenocarpus bataua Mart.

Socratea exorrhiza (Mart.) H.Wendl.

Syagrus inajai (Spruce) Becc.

buriti

bacaba

patauá

paxiúba

pupunha-brava

3

Bignoniaceae

Jacaranda copaia (Aubl.) D. Don

Tabebuia roseoalba (Ridl.) Sandwith

caroba

ipê-branco

1616

16

$\begin{array}{lll}8 & 9 & 17\end{array}$

$23 \quad 23$

$\begin{array}{lll}13 & 4 & 17\end{array}$

$\begin{array}{lll}1 & 6 & 7\end{array}$




\begin{tabular}{|c|c|c|c|c|}
\hline \multirow[t]{2}{*}{ Família/Espécie } & \multirow[t]{2}{*}{ Nome popular } & \multicolumn{3}{|c|}{$\mathrm{N}^{0}$ de indivíduos amostrados } \\
\hline & & F. Baixio & F. Encosta & Total \\
\hline \multicolumn{5}{|l|}{ Bixaceae } \\
\hline Bixa orellana L. & urucum & & 1 & 1 \\
\hline \multicolumn{5}{|l|}{ Boraginaceae } \\
\hline Cordia goeldiana Huber & freijó & & 2 & 2 \\
\hline Cordia nodosa Lam. & freijó-branco & & 4 & 4 \\
\hline \multicolumn{5}{|l|}{ Burseraceae } \\
\hline Protium apiculatum Swart & breu vermelho & 2 & 5 & 7 \\
\hline Protium spruceanum (Benth.) Engl. & breu branco & 5 & 22 & 27 \\
\hline Trattinnickia burserifolia Mart. & breu sucuruba & 5 & 9 & 14 \\
\hline \multicolumn{5}{|l|}{ Caryocaraceae } \\
\hline Caryocar villosum (Aubl.) Pers. & piquiá & 1 & & 1 \\
\hline \multicolumn{5}{|l|}{ Chrysobalanaceae } \\
\hline Couepia longipendula Pilg. & castanha-de-galinha & & 4 & 4 \\
\hline Licania canescens Benoist & caripe farinha & & 1 & 1 \\
\hline Licania lata J.F. Macbr. & caripé, macucu-bobo & 3 & 6 & 9 \\
\hline Licania laxiflora Fritsch & macucu roxo & 2 & & 2 \\
\hline Licania oblongifolia Standl. & macucu-chiador & 2 & & 2 \\
\hline Parinari parvifolia Sandwith & pajurazinho & 1 & & 1 \\
\hline \multicolumn{5}{|l|}{ Clusiaceae } \\
\hline Clusia renggerioides Planch. \& Triana & apuí & 2 & & 2 \\
\hline Symphonia globulifera L.f. & anani-do-baixio & 3 & & 3 \\
\hline Tovomita martiana Engl. & tovomita & 1 & & 1 \\
\hline \multicolumn{5}{|l|}{ Combretaceae } \\
\hline Buchenavia parvifolia Ducke & tanimbuca & 1 & 1 & 2 \\
\hline \multicolumn{5}{|l|}{ Ebenaceae } \\
\hline Diospyros kaki Thunb. & caqui & 1 & 5 & 6 \\
\hline \multicolumn{5}{|l|}{ Elaeocarpaceae } \\
\hline Sloanea guianensis (Aubl.) Benth. & urucurana & 2 & 5 & 7 \\
\hline \multicolumn{5}{|l|}{ Erythroxylaceae } \\
\hline Indeterminada 1 & ni & & 1 & 1 \\
\hline \multicolumn{5}{|l|}{ Euphorbiaceae } \\
\hline Alchornea discolor Poepp. & supiarana & 4 & 1 & 5 \\
\hline Anomalocalyx uleanus (Pax \& K. Hoffm.) Ducke & arataciú-preto & 49 & 1 & 50 \\
\hline Aparisthmium cordatum Baill. & mameleiro & 4 & 7 & 11 \\
\hline Conceveiba martiana Baill. & arraieira-branca & 2 & & 2 \\
\hline Croton lanjouwensis Jabl. & dima & & 2 & 2 \\
\hline $\begin{array}{l}\text { Hevea brasiliensis (Willd. ex A. Juss.) } \\
\text { Müll. Arg. Linnaea }\end{array}$ & seringueira & 1 & & 1 \\
\hline Hevea guianensis Aubl. & seringueira-vermelha & 12 & 1 & 13 \\
\hline Mabea subsessilis Pax \& K.Hoffm. & taquari & 12 & 14 & 26 \\
\hline Sagotia racemosa Baill. & arataciú & 4 & 3 & 7 \\
\hline
\end{tabular}




\begin{tabular}{|c|c|c|c|c|}
\hline \multirow[t]{2}{*}{ Família/Espécie } & \multirow[t]{2}{*}{ Nome popular } & \multicolumn{3}{|c|}{$\mathrm{N}^{\circ}$ de indivíduos amostrados } \\
\hline & & F. Baixio & F. Encosta & Total \\
\hline \multicolumn{5}{|l|}{ Fabaceae Caesalpinioideae } \\
\hline Dialium guianense (Aubl.) Sandwith & jutai pororoca & 1 & 1 & 2 \\
\hline Eperua glabriflora (Ducke) R.S. Cowan & muirapiranga & 7 & & 7 \\
\hline Swartzia panacoco (Aubl.) R.S. Cowan & coração-de-negro & & 1 & 1 \\
\hline Tachigali alba Ducke & tachi-branco & & 4 & 4 \\
\hline Tachigali myrmecophila (Ducke) Ducke & tachi-preto & & 1 & 1 \\
\hline \multicolumn{5}{|l|}{ Fabaceae Faboideae } \\
\hline Aldina heterophylla Spruce ex Benth. & macucu do baixio & 1 & & 1 \\
\hline Andira parviflora Ducke & sucupira-vermelha & & 1 & 1 \\
\hline Bowdichia nitida Spruce ex Benth. & sucupira-preta & & 1 & 1 \\
\hline Derris amazonica Killip & timborana & & 1 & 1 \\
\hline Derris negrensis Benth. & cipó timbozinho & & 1 & 1 \\
\hline Dipteryx odorata (Aubl.) Willd. & cumaru & 1 & 4 & 5 \\
\hline Hymenolobium sericeum Ducke & angelim-da-mata & & 1 & 1 \\
\hline Ormosia coccinea (Aubl.) Jacks. & tento grande & & 1 & 1 \\
\hline Pterocarpus officinalis Jacq. & mututi & 1 & & 1 \\
\hline Swartzia arborescens (Aubl.) Pittier & pau-chumbinho & & 1 & 1 \\
\hline Swartzia cuspidata Spruce ex Benth. & muirapiranga-branca & 2 & & 2 \\
\hline Swartzia reticulata Ducke & arabá-preto & 6 & 1 & 7 \\
\hline Swartzia schomburgkii Benth. & arabá-vermelho & 1 & 1 & 2 \\
\hline \multicolumn{5}{|l|}{ Fabaceae Mimosoideae } \\
\hline Enterolobium schomburgkii (Benth.) Benth. & moela-de-mutum & & 1 & 1 \\
\hline Enterolobium schomburgkii Benth. & orelha-de-macaco & & 1 & 1 \\
\hline Inga alba (Sw.) Willd. & ingá-vermelho & 11 & 22 & 33 \\
\hline Inga edulis Mart. & ingá-de-metro & & 1 & 1 \\
\hline Inga gracilifolia Ducke & ingá-xixica & 21 & 23 & 44 \\
\hline Inga paraensis Ducke & ingarana & 5 & 1 & 6 \\
\hline Inga umbratica Poepp. \& Endl. & ingá & 1 & & 1 \\
\hline Parkia decussata Ducke & arara-tucupi & 2 & & 2 \\
\hline Parkia multijuga Benth. & faveira-branca & 7 & 4 & 11 \\
\hline Parkia velutina Benoist & corezeiro & 12 & 6 & 18 \\
\hline Stryphnodendron guianense (Aubl.) Benth. & faveira-camuzé & 1 & 4 & 5 \\
\hline Zygia racemosa (Ducke) Barneby \& J.W.Grimes & angelim-rajado & 1 & 2 & 3 \\
\hline \multicolumn{5}{|l|}{ Goupiaceae } \\
\hline Goupia glabra Aubl. & cupiúba & 1 & 2 & 3 \\
\hline \multicolumn{5}{|l|}{ Humiriaceae } \\
\hline Endopleura uchi (Huber) Cuatrec. & uchui-grande & & 1 & 1 \\
\hline Sacoglottis ceratocarpa Ducke & achuá & & 1 & 1 \\
\hline Vantanea guianensis Aubl. & uchirana & 1 & & 1 \\
\hline Vantanea parviflora Lam. & uchirana & & 1 & 1 \\
\hline \multicolumn{5}{|l|}{ Hypericaceae } \\
\hline Vismia sandwithii Ewan & lacre-vermelho & 1 & & 1 \\
\hline Vismia guianensis (Aubl.) Pers. & lacre-branco & 1 & 6 & 7 \\
\hline
\end{tabular}




\begin{tabular}{|c|c|c|c|c|}
\hline \multirow[t]{2}{*}{ Família/Espécie } & \multirow[t]{2}{*}{ Nome popular } & \multicolumn{3}{|c|}{$\mathrm{N}^{0}$ de indivíduos amostrados } \\
\hline & & F. Baixio & F. Encosta & Total \\
\hline \multicolumn{5}{|l|}{ Iridaceae } \\
\hline Eleutherine bulbosa (Mill.) Urb. & marupari & 1 & & 1 \\
\hline \multicolumn{5}{|l|}{ Lauraceae } \\
\hline Aniba panarensis $\mathrm{Mez}$ & cheiroso & & 3 & 3 \\
\hline Dicypellium manausense W.A.Rodrigues & louro-preto & 1 & 8 & 9 \\
\hline Licaria cannella (Meisn.) Kosterm. & louro-pirarucu & 1 & 1 & 2 \\
\hline Ocotea argyrophylla Ducke & lorinho & & 6 & 6 \\
\hline Ocotea longifolia Kunth & louro-alcatrão & 2 & 1 & 3 \\
\hline Ocotea tabacifolia (Meisn.) Rohwer & louro-abacate & & 1 & 1 \\
\hline Persea americana Mill. & abacate & & 3 & 3 \\
\hline \multicolumn{5}{|l|}{ Lecythidaceae } \\
\hline Couratari guianensis Aubl. & tauari branco & 2 & 2 & 4 \\
\hline Eschweilera amazoniciformis S.A.Mori & matamatá & 4 & 14 & 18 \\
\hline Eschweilera collina Eyma & ripeiro-branco & 1 & & 1 \\
\hline Eschweilera romeu-cardosoi S.A.Mori & matamatá romeu & 1 & & 1 \\
\hline Gustavia elliptica S.A.Mori & mucurão & 1 & 2 & 3 \\
\hline Lecythis pisonis Cambess. & jarana & & 1 & 1 \\
\hline Lecythis poiteaui O.Berg. & jarana-amarela & & 1 & 1 \\
\hline \multicolumn{5}{|l|}{ Loganiaceae } \\
\hline Strychnos subcordata Spruce ex Benth. & murta-da-mata & & 3 & 3 \\
\hline \multicolumn{5}{|l|}{ Malpighiaceae } \\
\hline Byrsonima chrysophylla Kunth & murici & & 24 & 24 \\
\hline \multicolumn{5}{|l|}{ Malvaceae } \\
\hline Ceiba pentandra (L.) Gaertn. & sumaúma & & 1 & 1 \\
\hline Pachira aquatica Aubl. & mungubarana & & 1 & 1 \\
\hline Scleronema micranthum (Ducke) Ducke & cardeiro & 7 & 1 & 8 \\
\hline Sterculia pruriens (Aubl.) K. Schum. & xixá & & 1 & 1 \\
\hline Theobroma cacao L. & cacau & & 3 & 3 \\
\hline $\begin{array}{l}\text { Theobroma grandiflorum (Willd. ex Spreng.) } \\
\text { K. Schum. }\end{array}$ & cupuaçu & & 1 & 1 \\
\hline Theobroma subincanum Mart. & cupuí & 1 & & 1 \\
\hline Theobroma sylvestre Aubl. ex Mart. in Buchner & cacauí & 1 & 3 & 4 \\
\hline \multicolumn{5}{|l|}{ Melastomataceae } \\
\hline Bellucia dichotoma Cogn. & goiaba-de-anta & 1 & 5 & 6 \\
\hline Bellucia grossularioides (L.) Triana & goiaba-de-anta branca & 2 & 1 & 3 \\
\hline Miconia argyrophylla DC. & papa-terra & 1 & & 1 \\
\hline Miconia chrysophylla (Rich.) Urb. & buxixu & 1 & & 1 \\
\hline Miconia elaeagnoides Cogn. & buxixu orelha-de-burro & & 3 & 3 \\
\hline Miconia regelii Cong. & buxixu tinteiro & 4 & 6 & 10 \\
\hline Mouriri duckeanoides Morley & pitanga-da-mata & & 1 & 1 \\
\hline \multicolumn{5}{|l|}{ Meliaceae } \\
\hline Guarea sp. & jitorana & & 2 & 2 \\
\hline Trichilia micrantha Benth. & jitó & 5 & & 5 \\
\hline
\end{tabular}




\begin{tabular}{lcc}
\hline Família/Espécie & Nome popular & \multicolumn{2}{c}{ No de indivíduos amostrados $^{\circ}$} \\
& F. Baixio F.Encosta Total \\
\hline
\end{tabular}

\section{Moraceae}

Artocarpus altilis (Parkinson) Fosberg

fruta-pão

Brosimum acutifolium Huber

Brosimum longifolium Ducke

Brosimum parinarioides Ducke

Brosimum potabilie Ducke

Clarisia ilicifolia (Spreng.) Lanj. \& Rossberg

Ficus maxima Mill.

Helianthostylis sp.

Maquira calophylla (Poepp. \& Ednl.) C.C. Berg

Indeterminadaa 2

Sorocea guilleminiana Gaudich.

\section{Myristicaceae}

Iryanthera coriacea Ducke

Osteophloeum platyspermum

(Spruce ex A.DC.) Warb.

Virola caducifolia W.A.Rodrigues

Virola calophylla (Spruce) Warb.

Virola michelii Heckel

Virola pavonis (A.DC.) A.C.Sm.

\section{Myrtaceae}

Eugenia biflora (L.) DC.

Eugenia cf. biflora L.

Eugenia citrifolia Poir.

Psidium myrtoides O.Berg

Nyctaginaceae

Neea oppositifolia Ruiz \& Pav.

\section{Ochnaceae}

Ouratea discophora Ducke

Opiliaceae

Agonandra brasiliensis

Miers ex Benth. \& Hook. f.

\section{Oxalidaceae}

Averrhoa carambola $\mathrm{L}$.

Peraceae

Pogonophora schomburgkiana Miers ex Benth. amarelinho

\section{Piperaceae}

Piper colubrinum (Link ex Kunth) Link ex C. DC. pimenta longa

\section{Rhabdodendraceae}

Rhabdodendron amazonicum

(Spruce ex Benth.) Huber mururé

1

amapá

amapá-garrote

pau-rainha

pama

gameleira

helianthostylis

muiratinga

ni

matacalada

ucuuba-puña

ucuuba-chico-de-assis 1

ucuuba-peluda

ucuuba-vermelha

ucuuba-preta

ucuuba-do-baixio

murtinha branca

murta-grande

murtinha

araçá-do-mato

joão-mole

1

9

10

uxirana

1

1

pau-marfim

2

2

carambola

1

$1 \quad 1$

1

1

orelha-de-burro

2

2 


\begin{tabular}{|c|c|c|c|c|}
\hline \multirow[t]{2}{*}{ Família/Espécie } & \multirow[t]{2}{*}{ Nome popular } & \multicolumn{3}{|c|}{$\mathbf{N}^{0}$ de indivíduos amostrados } \\
\hline & & F. Baixio & F. Encosta & Total \\
\hline \multicolumn{5}{|l|}{ Rubiaceae } \\
\hline Borojoa sorbilis (Ducke) Cuatrec. & purui grande & & 1 & 1 \\
\hline Chimarrhis turbinata DC. & pau-de-remo & & 3 & 3 \\
\hline Duroia macrophylla Huber & purui grande & 1 & & 1 \\
\hline Duroia sprucei Rusby & purui da mata & 1 & & 1 \\
\hline Genipa americana $\mathrm{L}$. & jenipapo & & 2 & 2 \\
\hline Warszewiczia schwackei K.Schum. & rabo-de-arara & 1 & & 1 \\
\hline \multicolumn{5}{|l|}{ Rutaceae } \\
\hline Spathelia excelsa (Krause) R.S.Cowan \& Brizicky & surucucumirá & & 1 & 1 \\
\hline Zanthoxylum rhoifolium Lam. & tamanqueira & & 3 & 3 \\
\hline \multicolumn{5}{|l|}{ Salicaceae } \\
\hline Laetia corymbulosa Spruce ex Benth. & sardinheira & 1 & 4 & 5 \\
\hline Indeterminada 3 & ni & 1 & & 1 \\
\hline \multicolumn{5}{|l|}{ Sapindaceae } \\
\hline Cupania sp. & cupania & 1 & 7 & 8 \\
\hline Euphoria sp. & euphonia & 1 & 2 & 3 \\
\hline Talisia cupularis Radlk. & pitomba-da-mata & 1 & 6 & 7 \\
\hline \multicolumn{5}{|l|}{ Sapotaceae } \\
\hline Ecclinusa guianensis Eyma & abiurana-bacuri & 1 & & 1 \\
\hline Micropholis casiquiarensis Aubrév. & abiurana & & 2 & 2 \\
\hline Micropholis sp. & abiurana-do-baixio & 1 & & 1 \\
\hline Pouteria platyphylla (A.C.Sm.) Baehni & abiurana-vermelha & 1 & 4 & 5 \\
\hline Urbanella sp. & abiurana-de-massa & & 2 & 2 \\
\hline \multicolumn{5}{|l|}{ Simaroubaceae } \\
\hline Simarouba amara Aubl. & marupá & 1 & 2 & 3 \\
\hline \multicolumn{5}{|l|}{ Siparunaceae } \\
\hline Siparuna decipiens (Tul.) A.DC. & capitiu & 3 & 6 & 9 \\
\hline \multicolumn{5}{|l|}{ Solanaceae } \\
\hline Solanum vanheurckii Müll. Arg. & jurebebão & 2 & 1 & 3 \\
\hline \multicolumn{5}{|l|}{ Strelitziaceae } \\
\hline Phenakospermum guyannense (Rich.) Endl. & banana brava & 22 & 49 & 71 \\
\hline \multicolumn{5}{|l|}{ Urticaceae } \\
\hline Cecropia purpurascens C.C. Berg & imbaúba-roxa & 1 & 2 & 3 \\
\hline Cecropia sciadophylla Mart. & imbaubão & & 2 & 2 \\
\hline Pourouma bicolor Mart. & imbaúba & 2 & & 2 \\
\hline Pourouma guianensis Aubl. & imbaúba-benguê & 2 & 3 & 5 \\
\hline Pourouma minor Benoist & tourém-branco & 1 & 1 & 2 \\
\hline Pourouma villosa Trécul & imbaúba-branca & 1 & 3 & 4 \\
\hline Pourouma sp. & tourém-vermelho & 1 & & 1 \\
\hline \multicolumn{5}{|l|}{ Verbenaceae } \\
\hline Indeterminada 4 & ni & 1 & & 1 \\
\hline
\end{tabular}




\begin{tabular}{|c|c|c|c|c|}
\hline \multirow{2}{*}{ Família/Espécie } & \multirow[t]{2}{*}{ Nome popular } & \multicolumn{3}{|c|}{ Noo de indivíduos amostrados } \\
\hline & & F. Baixio & F. Encosta & Total \\
\hline \multicolumn{5}{|l|}{ Violaceae } \\
\hline Rinorea racemosa (Mart.) Kuntze & branquinha & 1 & 4 & 5 \\
\hline \multicolumn{5}{|l|}{ Vochysiaceae } \\
\hline Callisthene fasciculata Mart. & pau-jacaré & 1 & & 1 \\
\hline Erisma bicolor Ducke & mandioqueira roxa & 1 & & 1 \\
\hline Erisma uncinatum Warm. & quarubarana & 3 & 2 & 5 \\
\hline Qualea paraensis Ducke & mandioqueira & & 12 & 12 \\
\hline Vochysia biloba Ducke & guaruba & & 1 & 1 \\
\hline Indeterminada 5 & ni & 1 & 4 & 5 \\
\hline Morta & & 39 & 48 & 87 \\
\hline
\end{tabular}

